\title{
Non-invasive somatotransgenic bioimaging in living animals
}

\section{[version 1; peer review: 3 approved with reservations]}

\author{
Juliette M. Delhove1,2, Rajvinder Karda3 ${ }^{3}$ Lorna M. FitzPatrick4, \\ Suzanne M.K. Buckley33, Simon N. Waddington (103, Tristan R. McKay4
}

\footnotetext{
${ }^{1}$ Adelaide Medical School, Faculty of Health and Medical Sciences, University of Adelaide, Adelaide, South Australia, 5000, Australia

${ }^{2}$ Robinson Research Institute, University of Adelaide, Adelaide, South Australia, 5000, Australia

${ }^{3}$ Gene Transfer Technology Group, Institute for Women's Health, University College London, London, WC1E 6HX, UK

${ }^{4}$ Centre for Bioscience, Manchester Metropolitan University, Manchester, M15 6BH, UK
}

V1 First published: 09 Oct 2020, 9:1216

https://doi.org/10.12688/f1000research.25274.1

Latest published: 09 Oct 2020, 9:1216

https://doi.org/10.12688/f1000research.25274.1

\section{Abstract}

Bioluminescence imaging enables noninvasive quantification of luciferase reporter gene expression in transgenic tissues of living rodents. Luciferase transgene expression can be regulated by endogenous gene promoters after targeted knock-in of the reporter gene, usually within the first intron of the gene. Even using CRISPR/Cas9 mediated genome editing this can be a time consuming and costly process. The generation of germline transgenic (GLT) rodents by targeted genomic integration of a gene expression cassette in embryonic stem (ES) cells is commonplace but results in the wastage of large numbers of animals during colony generation, back-crossing and maintenance. Using a synthetic/truncated promoter-driven luciferase gene to study promoter activity in a given tissue or organ of a GLT also often results in unwanted background luciferase activity during whole-body bioluminescent imaging as every cell contains the reporter. We have developed somatotransgenic bioimaging; a method to generate tissue-restricted transcription factor activated luciferase reporter (TFAR) cassettes in rodents that substantially reduces the number of animals required for experimentation. Bespoke designed TFARs are delivered to newborn pups using viral vectors targeted to specific organs by tissue-tropic pseudotypes. Retention and proliferation of TFARs is facilitated by stem/progenitor cell transduction and immune tolerance to luciferase due to the naiive neonatal immune system. We have successfully applied both lentiviral and adeno-associated virus (AAV) vectors in longitudinal rodent studies, targeting TFARs to the liver and brain during normal development and in well-established disease models. Development of somatotransgenic animals has broad applicability to non-invasively determine mechanistic insights into homeostatic and disease states and assess toxicology and efficacy testing. Somatotransgenic bioimaging technology is superior to current whole-body, light-emitting transgenic models as it reduces the

\section{Open Peer Review}

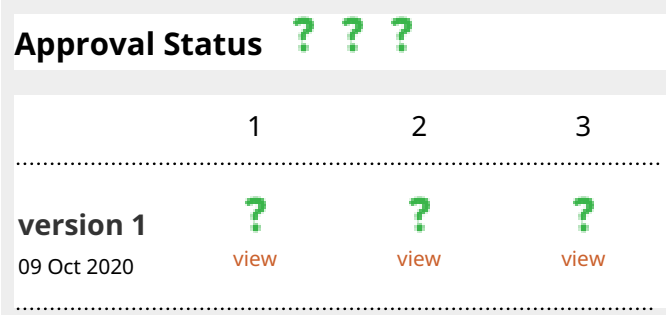

1. Tingting $X \mathbf{u}$, The University of Tennessee, Knoxville, USA

2. Antonius Plagge (ID), University of Liverpool, Liverpool, UK

3. Felicity Gavins ID, Brunel University

London, Uxbridge, UK

Any reports and responses or comments on the article can be found at the end of the article. 
numbers of animals used by generating only the required number of animals. It is also a refinement over current technologies given the ability to use conscious, unrestrained animals.

\section{Keywords}

somatotransgenic, luciferase, germline transgenic, biosensor, lentivirus, AAV

\section{NC \\ $3 R^{s}$}

This article is included in the NC3Rs gateway.

Corresponding author: Juliette M. Delhove (juliette.delhove@adelaide.edu.au)

Author roles: Delhove JM: Data Curation, Formal Analysis, Investigation, Methodology, Validation, Writing - Original Draft Preparation; Karda R: Data Curation, Formal Analysis, Methodology, Validation, Writing - Original Draft Preparation; FitzPatrick LM: Data Curation, Formal Analysis, Methodology, Validation; Buckley SMK: Data Curation, Formal Analysis, Investigation, Methodology, Project Administration, Supervision, Validation; Waddington SN: Conceptualization, Formal Analysis, Funding Acquisition, Investigation, Methodology, Resources, Supervision, Validation, Visualization, Writing - Original Draft Preparation; McKay TR: Conceptualization, Funding Acquisition, Methodology, Resources, Supervision, Writing - Original Draft Preparation

Competing interests: No competing interests were disclosed.

Grant information: This study was funded by the European Research Council grant "Somabio" [260862], National Centre for the Replacement, Refinement and Reduction of Animals in Research (NC3Rs) [NC/L001780/1] and the UK Medical Research Council.

Copyright: @ 2020 Delhove JM et al. This is an open access article distributed under the terms of the Creative Commons Attribution License, which permits unrestricted use, distribution, and reproduction in any medium, provided the original work is properly cited.

How to cite this article: Delhove JM, Karda R, FitzPatrick LM et al. Non-invasive somatotransgenic bioimaging in living animals [version 1; peer review: 3 approved with reservations] F1000Research 2020, 9:1216 https://doi.org/10.12688/f1000research.25274.1

First published: 09 Oct 2020, 9:1216 https://doi.org/10.12688/f1000research.25274.1 


\section{Research highlights:}

\section{Scientific benefits:}

- Rapid generation of a light-emitting transgenic; can be used in conjunction with whole-body transgenic animals to increase the amount of data obtained per animal and allows for within animal comparisons to be made making the data more reliable and sensitive.

\section{Rs benefits:}

- Reduced number of animals (a cohort of approximately 16 animals for multiple time points across the entire experiment compared to 16 animals PER time point); more data from same number of animals as serial measures can be performed; refined techniques to allow for conscious imaging; reduced anesthesia events which decreases animal distress leading to improved welfare of the animals.

\section{Practical benefits:}

- Time (weeks to generate and validate models compared to months to generate a whole-body transgenic and subsequently validate the model); less space required for transgenic colony; speed of experiments; cost benefit; easy to implement as long as a lab is already biosafety Class 2 compliant.

\section{Current applications:}

- Disease modelling (eg fibrosis, hypoxic ischemia, inflammation); monitoring of developmental pathways; mechanistic interrogation of molecular signaling pathways in embryonic and pluripotent stem cells (NRF2, NF-KB, PI3K, Wnt, TGFB, BMP, Notch).

\section{Potential applications:}

- Efficacy of drugs on candidate pathways.

\section{Introduction}

In the past, the study of gene expression during normal development or induced by disease in rodent models have been assessed largely by end-point assays involving the sacrifice of large cohorts of animals or restricted to invasive serial blood or urine sampling. Whole body imaging has been a game changer in this context and bioluminescence imaging (BLI) has become one of the most prevalent non-invasive modalities in academic research. Luciferase enzymes, derived from many different invertebrate species, catalyze their substrates in a reaction that emits photons of light in a dose responsive and quantifiable manner ${ }^{1}$. Bioluminescent light, resulting from the activity of luciferase genes optimized for expression in mammalian cells, can be used as a quantifiable surrogate for gene promoter activation in vivo and detected using highly sensitive charge-coupled device (CCD) cameras $^{2}$. Germline, light-producing transgenic (LPT) mice, where a luciferase transgene is inserted in the first intron of an endogenous gene, can be subjected to BLI to quantify gene activity in living animals ${ }^{3}$. Genome editing technologies have expedited the generation of whole body luciferase reporter transgenics ${ }^{4}$, and have massively increased the usage of LPT rodents, but critically do not reduce animal wastage in transgenic colony formation. In fact, the numbers of mice used in biomedical research has increased substantially since CRISPR/Cas9 genome editing has been applied to the production of transgenic mice with the time taken for mouse models to be created taking months instead of years to generate. The UK Home Office statistics notes that the number of procedures involving genetically altered animals rose by $36 \%$ between 2007 and 2016. Furthermore, it was reported that in 2016, 226,000 animals were used to create new lines of genetically altered animals ${ }^{5}$.

One of the greatest challenges facing users of germline LPT mice is that the luciferase reporter is present in every cell of the mouse. Researchers studying gene activity in a particular tissue or organ must be able to differentiate between target bioluminescence and the surrounding noise or targeting of the signal from a different organ entirely ${ }^{6}$. For many visceral organs this is practically impossible. We have developed an alternative approach by targeting conditionally activated luciferase reporter cassettes using viral vectors (lentivirus and adeno-associated virus) administered directly to target tissues in the newborn rodent to produce tissue-restricted somatotransgenic animals ${ }^{2}$. Viral transduction is further targeted by the use of pseudotyping with alternative viral envelopes known to have a specific cellular or tissue tropism $^{7}$. Resultant somatotransgenic rodents have tissue-restricted expression of a luciferase gene conditionally activated by a minimally defined promoter or a synthetic promoter. To date, we have designed and validated in vitro over 20 synthetic transcription factor activated reporter (TFAR) constructs based on a minimal promoter sequence activated by serial transcription factor binding motifs ${ }^{2}$. These reporter elements have been selected to interrogate some of the most common signaling pathways known to be aberrant in neurological diseases, cancer, fibrosis and drug toxicity, the details of which are highlighted in Table 1. Any small rodent can be subjected to somatotransgenic bioimaging (SB) and there is no colony breeding wastage.

Furthermore, SB can be layered on either gene knockout, chemically/biologically induced or naturally occurring rodent disease models ${ }^{2}$. The combined flexibility and reliability of SB means that the numbers of animals required for experiments is substantially reduced. As an example, a literature review of over 20 comparable studies of liver disease revealed that the common analytical methodologies were serial blood, bile and urine sampling involving repeated anaesthesia as well as periodic sacrifice for histological analysis. These involved large cohorts of between 3-12 animals being sacrificed at up to 10 timepoints meaning as many as 120 animals are used in each experiment. Typically, our experiments with somatotransgenic animals and longitudinal imaging contains 6-8 experimental and 6-8 control animals per experiment. This translates into a 7-10 fold reduction in the number of animals used as compared to the current standardmethodologies of analysis.

It is established that repeated anesthesia is not only distressing to rodents but also disrupts physiological and pathological processes, notably in the brain ${ }^{8}$. BLI is routinely carried out on anesthetized mice in order to define a photonic capture region of interest on a static target. Since SB is based on complete capture from a tissue-restricted luciferase reporter gene, rodents can remain conscious and unrestrained during imaging. Our comparisons 
Table 1. List of fully validated transcription factor activated luciferase reporter (TFAR) lentiviral vectors.

\begin{tabular}{|c|c|c|c|c|c|}
\hline $\begin{array}{l}\text { Response } \\
\text { Element }\end{array}$ & Disease Model & Response Element Sequence & In vitro agonist & $\begin{array}{l}\text { Activation } \\
\text { Duration } \\
\text { (Hours) }\end{array}$ & $\begin{array}{l}\text { Peak } \\
\text { Activation } \\
\text { (Hours) }\end{array}$ \\
\hline NFKB & Inflammation/Cancer & (GGGACTTTCC) $\times 8$ & LPS (100 ng/ul) & 4 & 24 \\
\hline SMAD $2 / 3$ & Fibrosis & $(A G C C A G A C A) \times 8$ & Activin A (100 ng/ $\mu \mathrm{l})$ & 72 & 72 \\
\hline $\begin{array}{l}\text { SMAD } \\
1 / 5 / 8\end{array}$ & Cancer/EMT & (CGCGGCGCCAGCCTGACAGCCCG) ×6 & 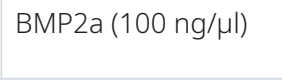 & 48 & 48 \\
\hline Hypoxia & Ischemia/ Cancer & $($ TACGTGCT) $\times 8$ & $\begin{array}{l}\mathrm{Low} \mathrm{O}_{2} / \\
\text { Cobalt chloride ( } 250 \\
\mu \mathrm{M} / \mu \mathrm{l})\end{array}$ & $72 / 12$ & $72 / 24$ \\
\hline TCF/LEF & Development & (AGATCAAAGGGGGTA) x8 & $\mathrm{LiCl}_{2}(50 \mathrm{mM})$ & 24 & 72 \\
\hline Estrogen & Cancer & (GTCAGGTCACAGTGACCTGAT) x4 & Estradiol (100 nM) & 15 & 72 \\
\hline p53 & Cancer & $\begin{array}{l}\text { (AGACATGTCCAGACATGTCCGAACATGT } \\
\text { CCCAACATGTTGT) } \times 4\end{array}$ & Nutlin-3A (25 $\mu \mathrm{M})$ & 24 & 72 \\
\hline AP-1 & Cancer & $($ TGAGTCAG) $\times 8$ & PMA (10 ng/ml) & 24 & 48 \\
\hline PI3K/Akt & Cancer/ Development & (GATCAAGTAAACAACTATGTAAACAA) $\times 4$ & LY294002 (20 mM) & 72 & 72 \\
\hline STAT3 & Cancer/ Development & (GTCGACATTTCCCGTAAATCGTCGA) x4 & $\operatorname{LIF}(10 \mu \mathrm{M})$ & 1 & 24 \\
\hline GLI-1 & Development & (GACCACCCAC) $\times 8$ & $\begin{array}{l}\text { Purmorphamine } \\
(10 \mu \mathrm{M})\end{array}$ & 4 & 12 \\
\hline HNF4- $\beta$ & Development/Toxicity & (GGCAAAGGTCAT) x8 & Linoleic acid & & \\
\hline NRF2 & Toxicity & (TCACAGTGACTCAGCAAAATT) $\times 8$ & $\mathrm{H}_{2} \mathrm{O}_{2}$ & 0.33 & 24 \\
\hline Xenobiotic & Toxicity & (TGAGTTCTCACGCTAGCAGAT) x8 & TCDD (10 nM) & 24 & 72 \\
\hline NFAT & Immunity & $\begin{array}{l}\text { (GGAGGAAAAACTGTTTCATACA } \\
\text { GAAGGCGT) x4 }\end{array}$ & $\begin{array}{l}\text { PMA }(10 \mathrm{ng} / \mathrm{ml}) \& \\
\text { ionomycin }(0.5 \mu \mathrm{M})\end{array}$ & 24 & 24 \\
\hline $\begin{array}{l}\text { Gluco- } \\
\text { corticoid }\end{array}$ & $\begin{array}{l}\text { Cardiovascular/ } \\
\text { Immunity }\end{array}$ & (GGTACATTTTGTTCT) $\times 8$ & $\begin{array}{l}\text { Dexamethasone } \\
(100 \mathrm{nM})\end{array}$ & 72 & 72 \\
\hline Notch & Cancer/ Development & (CGTGGGAA) x8 & $\begin{array}{l}\text { NICD (co-culture } \\
\text { with NICD- } \\
\text { overexpressing } \\
\text { cells) }\end{array}$ & 72 & 72 \\
\hline LXR & Hepatic Regeneration & (TGAATGACCAGCAGTAACCTCAGC) ×6 & T0901317 (500nM) & 72 & 72 \\
\hline ISL1 & Development & (TTAATGANNNNNNNNNNCTAATGA) x4 & Insulin & & \\
\hline TFEB & Autophagy & $($ TCACGTGA) $\times 8$ & Serum starvation & & \\
\hline
\end{tabular}

nuclear factor kappa-light-chain-enhancer of activated B cells (NFKB); lipopolysaccharide (LPS); bone morphogenetic protein 2a (BMP2a); T-cell factor/ lymphoid enhancer-binding factor (TCF/LEF); lithium chloride ( $\mathrm{LiCl}_{2}$ ); activator protein 1 (AP-1); phorbol myristate acetate (PMA); Leukemia inhibitory factor (LIF); hepatic nuclear factor 4 beta (HNF4- $\beta$ ); hydrogen peroxide $\left(\mathrm{H}_{2} \mathrm{O}_{2}\right) ; 2,3,7,8$-Tetrachlorodibenzo-p-dioxin (TCDD); nuclear factor of activated T-cells (NFAT); Notch intracellular domain (NICD); liver x receptor (LXR); transcription factor EB (TFEB).

of SB in brains and livers showed no difference between conscious or unconscious bioimaging?. This represents a significant refinement to animal husbandry, as well as increases the frequency with which rodents can be subjected to bioimaging. Thus meaning more data can be obtained from the same number of animals. SB can be used by any researcher in academia or industry with access to an appropriate in vivo imaging system, such as the IVIS ${ }^{\circledR}$ imaging platform, to detect BLI and assess changes in gene expression resulting from disease onset or drug intervention. 
Here we present methodologies describing the development of the viral reporter vectors, the production of TFAR-containing virus, and methods for in vitro validation. Technical details of our in vivo validations for 2 disease models of inflammation, bile duct ligation and a model of hyperoxia, are detailed and experimental data presented.

\section{Materials}

Design and construction of viral reporter vectors

$M l u \mathrm{I}$ (New England Biolabs; R0198S)

XhoI (New England Biolabs; R0146S)

BamHI (New England Biolabs; R0136S)

EcoRI (New England Biolabs; R0101S)

pENTR-1A® (Invitrogen; A10462)

cPPT forward sequencing primer - (GTGCAGGGGAAAGAATAG TAG)(Sigma-Aldrich)

Gateway $^{\mathrm{TM}}$ LR Clonase ${ }^{\mathrm{TM}}$ II enzyme mix (Invitrogen; 11791020)

DH5 $\alpha$ chemically competent cells (Invitrogen; 18258012)

One Shot ${ }^{\mathrm{TM}}$ Stbl3 ${ }^{\mathrm{TM}}$ competent cells (Invitrogen; C737303)

ampicillin antibiotic (Sigma-Aldrich; A9393)

LB agar (Sigma-Aldrich; L3027)

LB broth powder (Sigma-Aldrich; L3147)

agarose gel powder (Sigma-Aldrich; A4718)

Viral vector production and titering

HEK293T cell line (VWR; MSPP-CRL3216)

Dulbecco's Modified Eagle's Media (DMEM) (Sigma-Aldrich; D6429)

Fetal calf serum (FCS)(Invitrogen; 10082147)

Penicillin/Streptomycin (Pen/Strep) (Sigma-Aldrich; P4333)

Phosphate buffered saline (PBS) (Sigma-Aldrich; D8662)

Trypsin EDTA dissociation media (Sigma-Aldrich; T4299)

Opti-MEM I reduced serum medium (Invitrogen; 31985070)

pMD2.G (VSV-G envelope) (Addgene; \#12259)

pCMVd8.74 (gag-pol, tat, rev) (Addgene; \#22036)

PsPAX2 (Addgene \#12260)

RETRO-TEK HIV-1 p24 antigen ELISA (Zeptometrix; 0801200)

KAPA SYBR FAST qPCR kit (Roche; KK4600)

branched PEI (MW 25,000) (lentivirus production) (Sigma Aldrich; \#408727)

$0.45 \mu \mathrm{M}$ PVDF filter (Sigma-Aldrich; P1938)

pHGT1 Ad5 helper plasmid (MTA Harvard Medical School, USA)

Benzonase (Sigma-Aldrich; E8263)

AAV pro 293T cells (Takara; 632273)
Sodium chloride (Sigma-Aldrich; S9888)

Polyethyleneimine (PEI) (Polysciences; 24765)

$0.45 \mu \mathrm{m}$ filter membrane (Millipore; SCHVU05RE)

Cell lifter (Corning; 3008)

$0.45 \mu \mathrm{m}$ syringe filters (Sartorius; 17598)

$0.22 \mu \mathrm{m}$ centrifuge tube filter (Costar; 8160)

$10 \mathrm{ml}$ syringe (Terumo; SS+10ES1)

$50 \mathrm{ml}$ syringe (BD Plastipak; 300865)

Disposable needles (BD Microlance; 301155)

Benzonase nuclease (Sigma; E1014-25KU)

Amicon Ultra-15 centrifugal filter units (Millipore; UFC910024)

Slide-A-lyzer dialysis cassette 10,000 MWCO (Thermo Scientific; 66810)

5 ml FACS tubes (Falcon; 352053)

Sodium deoxycholate (Sigma; D6750-100G)

Glycine (Sigma; G8898-500G)

POROSTM CaptureSelect ${ }^{\mathrm{TM}}$ AAV Resin (Thermo Scientific; A36739)

ÄKTAprime plus (High performance liquid chromatography HPLC system (GE Healthcare; 11001313)

DPBS (1X) (Gibco; 14190-094)

PBS tablets (Sigma; P4417-100TAB)

Luna Universal Probe qPCR MasterMix (NEB; M3004S).

96-well PCR plate $0.1 \mathrm{~mL}$ format.

MicroAmp® Optical Adhesive Film (Applied Biosystems).

In vitro validation of the pLNT-HRE-Luc-eGFP

HeLa cell line (Sigma; 93021013)

Huh7 cell line (JCRB Cell Bank; JCRB0403)

HepG2 cell line (Sigma; 85011430)

RPMI-1640 media (Sigma-Aldrich; R8758)

ultra-pure LPS-EB (InvivoGen; tlrl-3pelps)

Activin A (PeproTech; AF-120-14E)

BMP2a (PeproTech; AF-120-02)

Cobalt Chloride (Sigma-Aldrich; 60818)

Lithium Chloride $\left(\mathrm{LiCl}_{2}\right)$ (Sigma-Aldrich; L9650)

Estradiol (Sigma-Aldrich; E2758)

Nutlin-3a (Sigma-Aldrich; SML0580)

Phorbol 12-myristate 13-acetate (PMA) (Sigma-Aldrich; P8139)

LY294002 (StemCell Technologies; \#72152)

human recombinant LIF (StemCell Technologies; \#78055)

Purmorphamine (Sigma-Aldrich; SML0868) 
Hydrogen peroxide $\left(\mathrm{H}_{2} \mathrm{O}_{2}\right)$ (Sigma-Aldrich; 216763)

2,3,7,8-tetrachlorodibenzo-p-dioxin (TCDD) (Sigma-Aldrich; NIST1614)

Ionomycin (Sigma-Aldrich; I0634)

Luciferase assay lysis buffer (0.65\% NP40 (Sigma-Aldrich; NP40), $10 \mathrm{mM}$ Trizma ${ }^{\circledR}$ base (Sigma-Aldrich; T1699) (pH 8.0), 1 mM Ethylenediaminetetraacetic acid (EDTA) (Sigma-Aldrich; E9884)(pH 8.0), 150 mM NaCl(Sigma-Aldrich; S9888))

luciferase assay buffer (25 mM Trizma ${ }^{\circledR}$ base (Sigma-Aldrich; T1699) pH 7.8, 1 mM 1,4-Dithiothreitol (DTT) (Sigma-Aldrich; 10197777001), 1 mM EDTA (Sigma-Aldrich; E9884), 1\% Triton ${ }^{\mathrm{TM}}$ X-100 (Sigma-Aldrich;), 8 mM MgCl (Sigma-Aldrich; M8266), $3 \mathrm{ml}$ glycerol (Sigma-Aldrich; G5516), 1.25 mM rATP (Promega; E6011), 0.5\% BSA (Sigma-Aldrich; A2153))

Luminometer such as the GloMax (Promega; E9032)

Bio-rad protein assay (Bio-rad; \#5000006)

Animal procedures

CD1 mice (Charles River Laboratories)

$4 \%$ isofluorane (Abbott Laboratories)

33-gauge Hamilton needle (Fisher Scientific, Loughborough)

bupivacaine hydrochloride (Advanz Pharma)

D-luciferin, potassium salt (Gold Biotechnologies; LUCK)

cooled charged-coupled device camera (IVIS machine) (Perkin Elmer)

Living Image Software (v4.1) (Perkin Elmer)

\section{Methods}

Design and construction of viral reporter vectors

Lentivirus cloning. A simple two-step cloning process was developed to generate lentiviral TFAR vectors using Gateway ${ }^{\circledR}$ cloning. We first generated the parental lentiviral vector by cloning the Gateway ${ }^{\circledR}(\mathrm{GW})$ Destination recombination site into a blunted unique $M l u \mathrm{I}$ restriction site of a $2^{\text {nd }}$ generation HIV-1 based lentiviral backbone upstream of a bicistronic 3xFLAG-FLuc-F2A-eGFP reporter gene cassette to produce pLNT-GW-Luc-eGFP. We then generated a shuttle vector containing the adenovirus E1A minimal promoter (MP) sequence cloned into a unique XhoI restriction site in the Gateway® shuttle vector, pENTR-1A. This shuttle plasmid (pENTR-MP) was used as a sub-cloning vector to introduce de novo synthesized regulatory sequences (Aldevron, North Dakota, USA) upstream of the MP (existing TFARs listed in Table 1) into BamHI/EcoRI restriction sites. Vectors were confirmed by Sanger sequencing using a cPPT forward primer (GTGCAGGGGAAAGAATAGTAG) then recombined into pLNT-GW-Luc-eGFP using Gateway® cloning (Figure 1A).

$\boldsymbol{A} \boldsymbol{A} \boldsymbol{V}$ cloning. The AAV8-Gateway®-Luc-T2A-eGFP was completely de novo synthesized (Aldevron). This AAV plasmid consisted of a Gateway ${ }^{\circledR}$ sequence, placed upstream of the Luc-2A-eGFP reporter cassette. AAV TFARs were generated by Gateway® cloning as with the lentiviral vectors (Figure 1B).

\section{Viral vector production and titering}

Both lentivirus and AAV vectors were generated by transfection of human embryonic kidney, HEK293T, producer cells with accessory plasmids as previously detailed ${ }^{2}$. Lentiviral titer was

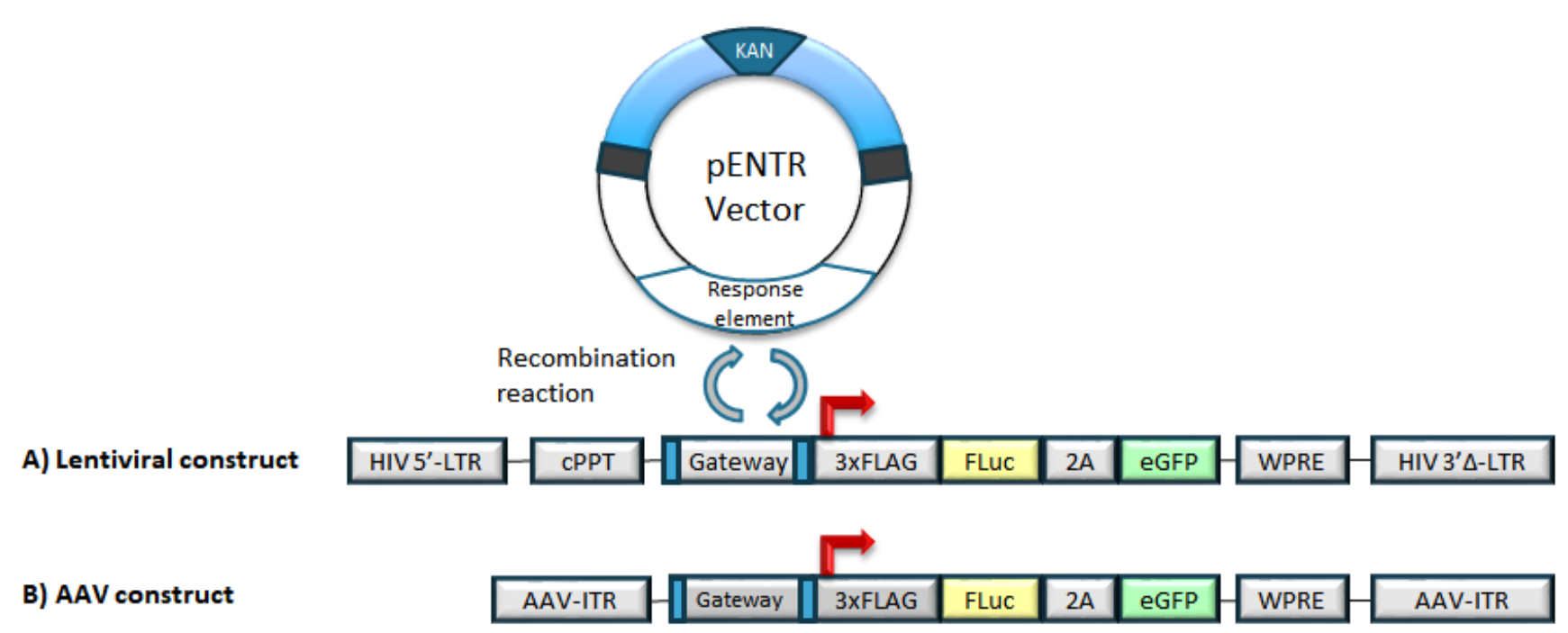

Figure 1. Gateway cloning to generate biosensing lentiviral and adeno-associated virus (AAV) constructs. Response elements are cloned into the pENTR vector. A recombination reaction is performed to shuttle the response element into the lentiviral or AAV backbone upstream of a 3 XFLAG-FLuc-2A-eGFP bicistronic reporter. 
generated based on the p24 ELISA assay whereas AAV was titered by quantitation of capsid protein by viral genome copy numbers per $\mathrm{ml}^{10,11}$.

\section{In vitro validation of the pLNT-HRE-Luc-eGFP construct}

All newly generated TFARs were comprehensively evaluated for predicted responses to known activators/inhibitors on multiple cell lines, including HEK293T, HeLa, Huh7, HepG2, and primary human fibroblasts, prior to being employed in vivo ${ }^{2}$. The reporters, in vitro agonists, concentrations, and duration of activation are outlined in Table 1.

Specifically, for the HIF response element (HRE) construct that can be used to determine the induction of hypoxia, HEK293T and HeLa cells were transduced with LNT-HRE-Luc-eGFP at a multiplicity of infection (MOI) of 10 . Three days post-transduction, transduced cells were replated in two sets of triplicates, one for HRE activation and one for basal levels of luciferase activity. The following day one triplicate set of cells were exposed to the agonist, $\mathrm{CoCl}_{2}(100 \mathrm{mM} / \mu \mathrm{l})$, in RPMI-1640 for 12 hours while the non-activated cells were only placed in RPMI-1640. A time course of $12,24,48$, and 72 hours post agonist activation was performed. At each time point, the cells were lysed in a standard luciferase assay lysis buffer and stored for future luciferase assay analysis.

\section{Animal procedures}

All procedures were performed under United Kingdom Home Office Project License 70/8030, approved by the ethical review committee, and followed institutional guidelines at University College London. All methods were performed in accordance with the relevant guidelines and regulations. Male and female outbred wild type CD1 mice were used and were supplied by Charles Rivers Laboratories. Mice were used for adult interventions as close as possible to 6 weeks of age and $25 \mathrm{~g}$.

IVC cages were used to house the mice, with a maximum of 5 per cage. Male and female mice were housed separately post weaning. Food and water were routinely monitored by the animal technicians at the facility. The temperature of the room was set at $25^{\circ} \mathrm{C}$ with light/dark cycles alternating every $12 \mathrm{hrs}$. Mice were bred onsite and time-mated in order to plan experiments as accurately as possible and avoid wastage of unused pups. A total of 34 mice were used in the studies, described below.

Neonatal intracranial and intravenous injections. Mice either received intracranial or intravenous injections, never both. Skilled technicians can achieve more than $99 \%$ success rate for intravenous injections and no failed intracranial injections. No anaesthesia was used as the procedure is very quick and involves a single needle puncture per mouse. For intracranial injections, mice (postnatal day $1(\mathrm{P} 1)$ ) received unilateral injections of concentrated lentiviral or AAV vector $(5 \mu \mathrm{l}$ in total) into the cerebral lateral ventricles using a 33-gauge Hamilton needle. The site of injection was located two-fifths of the distance between the eye and the lambda intersection of the skull as described and illustrated by Kim et $a l^{12}$. During the procedure, mice were held in an upright position, with their heads firmly placed between the handler's thumb and index finger. The 33-gauge Hamilton needle was held perpendicular to the mouse head and injected at a depth of approximately $3 \mathrm{~mm}$. The vector was slowly controlled and injected free handed into the lateral ventricles. At $\mathrm{P} 1$, a 33-gauge needle can easily penetrate the skull and there is no reflux of injectate as the ventricular system is sufficiently voluminous to accommodate the extra volume. Biodistribution of vector has been confirmed using this methodology ${ }^{9}$. For intravenous injections, $\mathrm{P} 1$ pups received intravenous injections of lentiviral or AAV vectors into the superficial temporal vein $(20 \mu \mathrm{l})$ using a 33-gauge Hamilton needle. This procedure was performed free handed over approximately 5 seconds. Pups were returned as soon as possible to the dam and the nest undisturbed as much as possible. Animals were monitored daily for distress or discomfort such as the presence of a dull/ruffled coat, poor posture (hunched), pale or sunken eyes, a change in normal behaviour, reduced food or water intake, dehydration, any discomfort when handled, a reluctance to move, and any significant weight loss. In this cohort, we noted no significant signs of pain or discomfort following vector administration.

\section{Validation and disease modelling induction of somatotransgenic bioimaging}

Effects of carrier gas on hypoxia-inducible factor (HIF) induction All mice received neonatal intracranial injection of lentivirus vector containing the HIF response element upstream of a luciferase-eGFP bicistronic cassette (LNT-HRE-Luc-eGFP) at P1. After weaning, age-matched mice were randomly allocated to two groups $(\mathrm{N}=11$ for each group based on power calculations) for imaging at $0,2,4,6$ and 8 hours. Randomization was achieved by using Microsoft Excel to generate a random column of numbers against mouse numbers and then sorting the list of mice using the SORT function. The groups received isoflurane mixed with either $100 \%$ oxygen or air. The group receiving $100 \%$ oxygen exhibited consistently lower HIF activation than the group receiving air ( $21 \%$ oxygen); this was significantly different at 6 hours $(P=0.0465$, repeated measures ANOVA where one factor was with/without $21 \%$ oxygen and the repeated measure was time). See data availability section.

This data suggests that the carrier gas, itself, may influence physiological and pathological processes and supports the concept that conscious bioimaging may be preferable, where possible?

\section{Partial bile duct ligation in mice}

All mice received neonatal intravenous injection of lentivirus vector containing the truncated GFAP promoter driving a luciferaseeGFP bicistronic cassette (LNT-GFAP-Luc-eGFP) at P1.

Mice were anaesthetized with $4 \%$ isoflurane at between $40-60$ days after birth, shaved and disinfected around the surgical area, and a midline laparotomy $(\approx 15 \mathrm{~mm})$ performed just caudal to the sternum using aseptic surgery techniques. The median and left lobes of the liver were exteriorized and kept moist with sterile gauze. The bile duct was ligated with 6.0 silk suture to occlude outflow from the left and median lobes but not occlude bile outflow from the right and caudate lobes as described by Yang 
and colleagues ${ }^{13}$. The liver was returned to the abdomen and the wound closed in two stages using 6.0 silk suture; skin was closed using a subcuticular suture with buried knots $(\mathrm{N}=7)$. Sham operated mice received laparotomy only $(\mathrm{N}=5)$. Mice were recovered in a warmed chamber and monitored to make sure they were not under any unnecessary distress. Clinical record sheets were used to detail observations and post-operative treatments that were given. Pre- and immediate post-operative doses of topical bupivacaine hydrochloride $(2 \mathrm{mg} / \mathrm{kg})$ and subcutaneous $50 \mu \mathrm{l}$ morphine $(6.67 \mathrm{mg} / \mathrm{ml})$ was administered for systemic post-operative analgesia ${ }^{14}$. Following surgery, mice were single housed and provided with moist food to aid consumption of food and prevent significant weight loss. Monitoring sheets recorded age, weight, disease and surgical status. Mice were monitored for approximately 1 hour post-surgery, and subsequently checked and weighed to monitor for overt signs of discomfort and significant weight loss. A loss of weight of more than $15 \%$ required humane euthanasia of the animal. In this cohort, the animals were not found to have negative post-operative outcomes, which is a significant improvement over performing full bile duct ligations which often result in pain, jaundice, and death to the animals. No animals within our cohort required euthanasia using partial bile duct ligation.

Whole-body bioluminescence imaging. Mice which underwent partial bile-duct ligations were anesthetized with isoflurane containing $100 \%$ oxygen, all other cohorts of mice described herein were imaged while conscious and free-moving. Mice received an intraperitoneal injection of $15 \mathrm{mg} / \mathrm{mL}$ of D-luciferin. Mice were imaged after 5 minutes using a cooled charged-coupled device camera (IVIS imaging machine) for between 1 second and 5 minutes. The regions of interest (ROI) were measured using Living Image Software and expressed as photons per second per centimeter squared per steradian (photons $/$ second $/ \mathrm{cm}^{2} / \mathrm{sr}$ ). The imaging chambers used to image conscious mice for the intracranial injected mice had the following dimensions; $5 \mathrm{~cm} \times 5 \mathrm{~cm}$ $\times 6 \mathrm{~cm}$. The Perspex box which was used to image the conscious mice which had received an intravenous injection is described in detail in Karda et al. ${ }^{9}$. Where possible, BLI was carried out in adult reporter rodents on three consecutive days to establish a robust median baseline; subsequent data points were expressed as fold-change over this internal standard for each individual animal.

Euthanasia. At experiment conclusion, mice were culled using rapid cervical dislocation to induce rapid loss of consciousness. To reduce the possibility of operator error, the main concern for animal welfare using this technique, the procedure was performed by adequately trained personnel with a high degree of technical proficiency only. Where possible, cervical dislocation was performed while mice were still under non-recovery isoflurane anaesthetic. Death was assured by decapitation.

\section{Statistics}

In consultation with a statistician, power calculations are performed based on previous data using the free GPower (v3.0.10) online software. Using the probability of finding an effect set at $80 \%$, the probability of incorrectly rejecting the null hypothesis when it is true set at 0.05 (alpha), and using a two-sided test, a power calculation was performed in order to determine the sample size required for each group under investigation. Using our previous data involving the activation of the Smad2/3 binding element using the potent agonist, activin A, a standard deviation of 1.75 was used. The mean of group 1 (control) was set at 5.13, and the mean of group 2 was set at 7.8 (experimental). Based on these values, the effect size is expected to be large (1.52 fold change). An effect size greater than 0.8 is indicative of a large effect size, indicating that $93 \%$ of the control group will be below the mean of the experimental group. The experiment was sufficiently powered with a sample size of eight experimental and eight control animals to detect a change in the total amount of photonic output between two groups with a power of $80 \%$. For in vivo data, repeated measurements following agonist administration were analyzed with repeated measures analysis of variance using GraphPad Prism v8.0.0 with a significance level of $\mathrm{P}<0.01$. Area under curve data for experiments with two groups were analyzed by Student's one-tailed t-test. For areas under curve derived from two or more groups, one-way analysis of variance (ANOVA) with Newman-Keuls post-hoc multiple comparison test was performed.

\section{Protocols}

We have generated a comprehensive library of lentiviral TFAR vectors and are developing a similar library of AAV vectors (Table 1). These TFARs are available to any academic researcher on request. We also have developed a simple two-step protocol for shuttling de novo synthesized transcription factor binding sequences into our parental vectors.

\section{Design and cloning of synthetic promoters into viral vectors, vector production, and in vitro validation}

\section{TFAR design, synthesis, and sub-cloning}

1. Derive minimal consensus binding sequence for the candidate transcription factor from the literature.

2. Design serial transcription factor binding sequence (TFBS) by interspersing 4-10 binding sequences with 10 random nucleotides using non-coding combinations of the 4 nucleotides.

3. De novo synthesize the resultant sequence flanked by BamHI (5'-) and EcoRI (3'-) restriction sites for directional cloning into pENTR-MP, a Gateway pENTR vector containing a minimal promoter sequence 5'GGGCTATAAAAGGGGGTGGGGGCGCGTTCGTCCTCACTCTCTTCC-3'.

4. Clone TFBS into pENTR-MP using DH5 $\alpha$ chemically competent cells to produce pENTR-TFAR.

5. Confirm clones by sequencing using the pENTR forward primer which binds approximately $82 \mathrm{bp}$ from the BamHI cloning site. (ACTGATAGTGACCTGTTCGTTGC).

\section{Cloning synthetic promoter into the lentiviral cassette.}

1. Perform a single-step LR Clonase recombination reaction between the pENTR-MP vector containing the desired synthetic promoter with the LNT-GW-Luc-eGFP vector as per manufacturer's standard instructions.

2. Transform $1 \mu \mathrm{l}$ of the LR recombination reaction into One Shot $^{\mathrm{TM}} \mathrm{Stbl}^{\mathrm{TM}}$ (Invitrogen) competent cells and grow 
cells overnight at $30^{\circ} \mathrm{C}$ on ampicillin-laden $(100 \mu \mathrm{g} / \mathrm{ml})$ LB-agar plates.

3. Select colonies and grow in a shaking incubator ( $280 \mathrm{rpm})$ overnight at $30^{\circ} \mathrm{C}$ in $5 \mathrm{mls}$ of $\mathrm{LB}$ broth containing ampicillin $(100 \mu \mathrm{g} / \mathrm{ml})$.

4. Screen and select colonies for positive clones using the BamHI restriction enzyme and gel electrophoresis. Correct clones contain 4 fragments of 10,928, approximately 200-300 bp (depending on response element and minimal promoter cloned in), $81 \mathrm{bp}$, and $12 \mathrm{bp}$ (not seen on gel). A plasmid that has not undergone recombination and is still the LNT-GW-Luc-eGFP parental backbone that does not contain the biosensing response element contains 5 fragments of the following sizes: 10, $928 \mathrm{bp}$, 857 bp, 702 bp, 228 bp, 12 bp (not seen on gel). Example gel provided as underlying data ${ }^{15}$.

5. Confirm clones by sequencing following the recombination reaction into the lentiviral backbone by using the cPPT forward primer (GTGCAGGGGAAAGAATAGTAG).

\section{Cloning synthetic promoters into the AAV cassette.}

1. As described above for cloning synthetic promoters into the lentiviral cassette, perform LR Clonase recombination reaction between pENTR-MP containing the synthetic promoter of choice with the AAV-GW-Luc-eGFP, as per manufacture's protocol (see Note $\mathbf{1}$ for Clonase storage recommendations).

2. Transform $1 \mu \mathrm{l}$ of the LR recombination reaction into One Shot ${ }^{\mathrm{TM}}$ Stbl3 ${ }^{\mathrm{TM}}$ (Invitrogen) competent cells (see Note 2) and grow cells overnight at $30^{\circ} \mathrm{C}$ on ampicillin-laden $(100 \mu \mathrm{g} / \mathrm{ml})$ LB-agar plates.

3. Select colonies and grow in a shaking incubator $(280 \mathrm{rpm})$ overnight at $30^{\circ} \mathrm{C}$ in $5 \mathrm{mls}$ of $\mathrm{LB}$ broth containing ampicillin $(100 \mu \mathrm{g} / \mathrm{ml})$.

4. Screen colonies for positive clones using appropriate restriction enzyme depending on the desired synthetic promoter and then perform gel electrophoresis.

\section{Notes}

Design and cloning of synthetic promoters into viral vectors

1. The LR Clonase enzyme mix is unstable even at $-20^{\circ} \mathrm{C}$ for extended periods. Thus, it is recommended that small aliquots of $5 \mu \mathrm{l}$ are made and preferably stored at $-80^{\circ} \mathrm{C}$ to reduce the number of freeze/thaw cycles and retain as much enzyme activity.

2. One Shot ${ }^{\mathrm{TM}}$ Stbl3 ${ }^{\mathrm{TM}}$ competent cells have been designed specifically for the propagation of unstable DNA sequence such as those found within the lentiviral backbone which contains direct repeats.

\section{Generation of high-titer TFAR lentivirus.}

1. Seed HEK293T cells (mycoplasma negative - see Note 3) at approximately $2 \times 10^{7}$ cells per $\mathrm{T} 175 \mathrm{~cm}^{2}$ flask and incubate at $37^{\circ} \mathrm{C}, 5 \% \mathrm{CO}_{2}$ overnight to achieve up to $90 \%$ confluence.

2. Mix lentiviral plasmids in Opti-MEM ${ }^{\mathrm{TM}}$ I reduced serum medium (7.5 mls / T175 flask) in the following quantities (per flask): $50 \mu \mathrm{g}$ transfer vector containing transgene, $32.5 \mu \mathrm{g}$ gag-pol packaging vector (pCMV $\Delta \mathrm{R} 8.74)$ OR psPAX2 and $17.5 \mu \mathrm{g}$ VSV-G envelope vector (pMD2.G).

3. In a separate tube, mix $1 \mu \mathrm{l} 10 \mathrm{mM}$ branched PEI in 7.5 mls Opti-MEM ${ }^{\mathrm{TM}}$ I reduced serum medium ${ }^{\circledR}$ (per flask). Incubate for 5 minutes.

4. Mix DNA and PEI solutions together in a 1:1 ratio (total of $15 \mathrm{mls}$ per flask) and incubate at room temperature for 20 minutes to allow DNA:PEI complexes to form (see Note 4 for PEI preparation using branched PEI). This is hereon described as transfection media (Opti-MEM, DNA:PEI complex).

5. Remove media from cells in flask and add $15 \mathrm{mls}$ of transfection media.

6. Incubate transfection media on cells in an incubator at $37^{\circ} \mathrm{C} / 5 \% \mathrm{CO}_{2}$ for 3 hours.

7. Remove transfection media and replace with $15 \mathrm{mls}$ complete media (DMEM + 10\% FCS + 1\% Pen/Strep).

8. After 24 hours, remove media and replenish cells with new culture medium.

9. After a further 48 hours, collect the virus-containing medium and filter through a $0.45 \mu \mathrm{m}$ PVDF filter (see Note 5).

10. Subject virus-containing medium to overnight centrifugation (16-20 hours) at $5000 \mathrm{~g}$ at $4^{\circ} \mathrm{C}$.

11. Repeat harvest and overnight centrifugation for 72-hour post-transfection supernatant.

12. Resuspend the viral pellet in $50 \mu \mathrm{l}$ Opti-MEM I reduced serum medium ${ }^{\circledR}$ (per T175 flask of cells used) and gently mix every 20 minutes for 1 hour at $4^{\circ} \mathrm{C}$ and cryopreserve at $-80^{\circ} \mathrm{C}$.

13. Lentiviral titer is obtained using a RETRO-TEK HIV-1 p24 antigen ELISA as per manufacturer's protocol.

\section{Generation of high-titer TFAR AAV.}

1. Seed 6-7 $\times 10^{6} \mathrm{HEK} 293 \mathrm{~T}$ cells into $15 \mathrm{~cm}$ plates so that they are $70-80 \%$ confluent and incubate at $37^{\circ} \mathrm{C}, 5 \%$ $\mathrm{CO}_{2}$ overnight.

2. Mix $10.5 \mu \mathrm{g}$ of the AAV transgene plasmid, $10.5 \mu \mathrm{g}$ of pDG8 plasmid expressing AAV2 Rep, AAV8 Cap gene and $31.5 \mu \mathrm{g}$ pHGT1 (Ad helper plasmid) to $1.5 \mathrm{mls}$ of OptiMEM reduced serum medium. Add $758 \mu \mathrm{l}$ of stock transfection agent PEI $(2 \mathrm{mg} / \mathrm{ml})$ to Opti-MEM (1.5ml/dish), mix and leave at room temperature for 15-20 minutes.

3. Drop-wise, add $3 \mathrm{ml}$ of transfection mix to each dish and gently distribute 
4. After 24 hours remove media and replace with $15 \mathrm{mls}$ of DMEM (2\% fetal calf serum and 1\% Pen/Strep antibiotic)

5. After 48 hours harvest the cells by scrapping the cells off the dish and pooling the media and cells to $50 \mathrm{ml}$.

6. Spin at $1500 \mathrm{rpm}^{*}$ for 5 minutes and pour supernatant into a receiver bottle and store at $-20^{\circ} \mathrm{C}$. ${ }^{*}$ revolutions per minute (herein, on a centrifuge with size of rotor radius $17.4 \mathrm{~cm})$

7. Re-suspend pelleted cells in $1 \mathrm{ml}$ TD lysis buffer $(140 \mathrm{mM}$ $\mathrm{NaCl}, 5 \mathrm{mM} \mathrm{KCl}, 0.7 \mathrm{mM} \mathrm{K}_{2} \mathrm{HPO}_{4}, 3.5 \mathrm{mM} \mathrm{MgCl}_{2}$, $25 \mathrm{mM}$ Tris. $\mathrm{pH} 7.5$ ), pool and store in $-80^{\circ} \mathrm{C}$.

8. Freeze thaw pellet 5 times and add $25 \mathrm{ul} / \mathrm{ml}$ of $20 \%$ sodium deoxycholate.

9. Add $8 \mathrm{ul} / 40 \mathrm{mls}$ of cells Benzonase and incubate at $37^{\circ} \mathrm{C}$ for 30 minutes. Spin at $4000 \mathrm{rpm}$ for 30 minutes at $18^{\circ} \mathrm{C}$ and filter using 0.45 um filters. Repeat this twice.

10. For supernatant, aliquot into $50 \mathrm{mls}$ tubes and add $5 \mathrm{ul}$ of benzonase per $50 \mathrm{mls}$ of supernatant.

11. Add $100 \mathrm{ul}$ of $\mathrm{MgSO}_{4}$ and incubate for 30 minutes at $37^{\circ} \mathrm{C}$, after which spin at $4000 \mathrm{rpm}$ for 30 minutes at $4^{\circ} \mathrm{C}$. Filter using 0.45 um filters, repeat twice.

12. Run the cell pellet and supernatant through the HPLC machine using the POROS column ${ }^{16}$.

13. Add virus to dialysis cassette and place cassette into $1 \mathrm{~L}$ of PBS. Keep spinning overnight at room temperature on a slow rotating rotor.

14. Prime the membrane of the Amico Ultra tube by adding $5 \mathrm{mls}$ PBS and centrifuge for 5 minutes at $4000 \mathrm{rpm}$.

15. Remove PBS and place virus onto membrane. Spin at $4000 \mathrm{rpm}$ for 5 minutes

16. Wash membrane with vector collected and add additional 100 ul PBS. Place vector into a $2 \mathrm{ml}$ centrifugal tube with 0.22 um filter. Spin for 3 minutes at $13,000 \mathrm{~K}$ on a benchtop centrifuge.

17. Remove filter and aliquot vector. Store at $-80^{\circ} \mathrm{C}$.

18. AAV vector was quantified using $\mathrm{qPCR}$ as per previously published protocol ${ }^{16}$, but briefly, samples were treated with DNase to release DNA. Serial dilutions were prepared to be used as standards. Both standards and samples were tested in triplicate. Cycling parameters were: $95^{\circ} \mathrm{C}$ for 10 minutes, followed by $40-45$ cycles of $95^{\circ} \mathrm{C}$ for 15 seconds and $60^{\circ} \mathrm{C}$ for 45 seconds. Vector titers were calculated using the following formula: Titre $(\mathrm{vc} / \mathrm{mL})=\mathrm{C} / 5 \times 1000 \times \mathrm{D} \times 10 \times 2($ See note 6$)$.

\section{Notes}

\section{Lentiviral and AAV vector production}

3. Mycoplasma infections have the capacity to reduce lentiviral titers. Therefore, perform a mycoplasma test using
PCR with the following primers: Forward (5'- gggagcaaacaggattagataccet - 3') and Reverse (5'- tgcaccatctgtcactctgttaacctc $-3^{\prime}$ ) with the following cycling parameters: $94^{\circ} \mathrm{C}$ for 30 seconds, $55^{\circ} \mathrm{C}$ for 30 seconds and $72^{\circ} \mathrm{C}$ for 30 seconds repeated for 30 cycles. A $1.5-2 \%$ gel will yield a 300 bp fragment on an agarose gel. Alternatively use a fluorescence-based method using a kit such as MycoAlert ${ }^{\mathrm{TM}}$ Mycoplasma Detection kit (Lonza).

4. To make up $10 \mathrm{mM}$ branched PEI $\left(\mathrm{M}_{\mathrm{w}} \sim 25,000\right)$, in a fume hood, add $10 \mathrm{ml}$ water to $10 \mathrm{ml}$ PEI and vortex. Add $12 \mathrm{~N} \mathrm{HCL}, 1 \mathrm{ml}$ at a time, and vortex (this is approximately $10 \mathrm{ml} \mathrm{HCL}$ ) then top up to $41.2 \mathrm{ml}$ with water. Make sure that this final solution is at $\mathrm{pH}$ 7.0. Vortex and store in small aliquots at $-80^{\circ} \mathrm{C}$.

5. Both PES and PVDF filters are suitable but PVDF has been shown to be lower protein binding.

6. Where $\mathrm{C}$ is the copy number measured from the reaction, 5 is the volume of sample used, 1000 is the conversion factor from $\mu \mathrm{l}$ to $\mathrm{ml}, \mathrm{D}$ is the dilution factor, 10 is the initial dilution of the AAV from the digestion $(5 \mu \mathrm{l}$ to $50 \mu \mathrm{l})$, and 2 takes into account the complementary strand that is not targeted by the primers within the reaction.

\section{In vitro validation of HRE reporter constructs.}

1. Plate cell lines at $\sim 60 \%$ confluence and transduce with virus at an MOI of 10 .

2. Amplify transduced cells for at least 72 hours before replating to allow the virus to integrate and express basal levels of the transgenes.

3. Add $250 \mu \mathrm{M} \mathrm{CoCl}$ in RPMI-1640 media to activate HRE activity for 12 hours followed by addition of $500 \mu \mathrm{l}$ of RPMI-1640 media (see note 6).

4. At 24 hours post-activation, replace with complete media.

5. For luciferase activity, lyse approximately $5 \times 10^{5}$ cells in $300 \mu \mathrm{l}$ luciferase lysis buffer $(0.65 \%$ NP40, $10 \mathrm{mM}$ Trizma ${ }^{\circledR}$ base (pH 8.0), 1 mM EDTA (pH 8.0), $150 \mathrm{mM}$ $\mathrm{NaCl})$

6. Clarify the soluble fraction of the supernatant by centrifugation at $13,000 \mathrm{xg}$ for 1 minute.

7. Add $20 \mu \mathrm{l}$ cell extract to $20 \mu \mathrm{l}$ assay buffer $\left(25 \mathrm{mM}\right.$ Trizma ${ }^{\circledR}$ base $\mathrm{pH}$ 7.8, $1 \mathrm{mM}$ DTT, $1 \mathrm{mM}$ EDTA, $1 \%$ Triton $^{\mathrm{TM}}$ $\mathrm{X}-100,8 \mathrm{mM} \mathrm{MgCl}, 3 \mathrm{ml}$ glycerol, $1.25 \mathrm{mM}$ rATP, $0.5 \% \mathrm{BSA})$.

8. Inject D-luciferin substrate (Gold Biotechnology) into each well at a final concentration of $1.5 \mathrm{mM}$.

9. Measure luminescence output using a suitable microplate reader with luminescent capabilities.

10. Perform a protein assay to normalise relative photonic light units to total protein. 
11. Only if a statistically significant response to agonist or antagonist was achieved, using appropriate statistical evaluation, would the TFAR be deemed suitable for in vivo experiments.

\section{Notes}

In vitro validation of HRE biosensing construct

6. It is important to note that histidine inhibits $\mathrm{CoCl}_{2}$, and DMEM contains high concentrations of histidine compared to other media. It is therefore imperative to use RPMI-1640 for HRE induction using this agonist.

\section{Neonatal Intracranial and Intravenous injections}

1. Administer concentrated lentiviral or AAV vector $(5 \mu \mathrm{l}$ total) by unilateral injection into the cerebral lateral ventricles using a 33-gauge Hamilton needle (see note 7).

2. Perform intravenous injections of lentiviral or AAV vectors $(20 \mu \mathrm{l}$ total $)$ into the superficial temporal vein using a 33-gauge Hamilton needle.

\section{Continued monitoring of TFAR activity in anesthetised or conscious mice}

1. As previously described ${ }^{9}$, anesthetize mice (see Note 8) with $4 \%$ isofluorane in $100 \% \mathrm{O}_{2}$ (see Note 9). Inject $300 \mu \mathrm{l}$ D-luciferin solution at a concentration of $15 \mathrm{mg} / \mathrm{ml} \mathrm{(a}$ dose of approximately $150 \mathrm{mg} / \mathrm{kg}$ ) into the intraperitoneal cavity (see Note 10).

2. Image the unconscious mice in the warmed lightproof detection chamber of the IVIS in vivo imaging system (see Note 11). Commence imaging 5 minutes after D-luciferin administration ( $\mathrm{t}=0$ ) (see Note 12). An overlay of the two images is generated using Living Image software to create a pseudo-colored image to depict luminescent intensities over each animal.

3. Define regions of interest (ROIs) manually using a standard area for each organ.

4. Prior to agonist-mediated activation or surgical induction of disease, each of the animals is administered with D-luciferin and imaged three times within 72 hours in order to ascertain a robust median baseline measurement of bioluminescent imaging which can subsequently be used to express all future data points as a fold-change over this baseline value.

5. The type of statistical test depends upon the nature of the biosensor and the kinetics of the response. Two possible approaches are; A) for each animal in the two experimental groups, obtain the area under the curve using the parallelogram method. Compare using a Student's t-test if data is normally distributed. If mathematical transformations were not sufficient to satisfy parametric assumptions we suggest using a non-parametric test e.g. Mann-Whitney U-test. B) compare two or more experimental groups over time using analysis of variance (ANOVA) with repeated measures. If ANOVA shows a significant difference between groups, perform a post-hoc test (e.g. Tukey, Bonferroni or Sidak) to test which time points might be significantly different (see Note 13).

\section{Notes}

Continued monitoring of TFAR activity in anesthetised or conscious mice

7. The 33-gauge Hamilton needle should be kept moist at the tip by placing a wet paper towel around the needle. This helps reducing the friction against the new-born mouse skin.

8. Mice can be injected without anesthesia. However, anesthesia reduces mobility and improves injection accuracy. Inhalation or injectable anesthetics are avoided as the nose cone impairs access to the injection sites (especially the superficial temporal vein).

9. Mice may also be anesthetized using air or air and a nitrous oxide mix. The choice of carrier gas may affect the chosen biosensor as well as firefly luciferase activity (since this is an oxygen-dependent reaction).

10. When administering the D-luciferin via intraperitoneal injection, make sure that the bladder or other internal organs are not penetrated by the needle. This can be achieved by "tenting" the skin for injection. Similarly, ensure penetration into the peritoneal cavity by watching for, and avoiding the formation of a subcutaneous bleb.

11. To achieve optimal luciferase expression from the mice, it is best to use white furred mice as the black-furred mice prevent the bioluminescence from penetrating through.

12. Waiting 5 minutes after D-luciferin administration permits time for entry of the D-luciferin into the bloodstream. It is worth performing a preliminary experiment to determine the kinetics for optimal bioluminescence for different cell and tissue targets. In addition, alternative routes of D-luciferin administration (e.g. intranasal) may be used.

13. It is good practice to perform a preliminary experiment to gauge the kinetics of the biosensor response and to identify timeframes of these responses in order to refine subsequent statistical tests. The statistical test and the time points of analysis should be decided before the experiment is performed, not afterwards.

\section{Results}

\section{Hypoxia and hyperoxia biosensing}

Lentiviral delivery of vectors containing transcription factor binding elements upstream of a bicistronic reporter cassette offer a unique method with which to interrogate biological pathways. HRE is used as a biological sensor of hypoxia, important in 
cancer and ischemia models of disease. Here we present data validating our biosensing constructs in vitro (Figure 1) prior to in vivo (Figure $2^{15}$ ) validation and experimentation.

In vitro validation of the pLNT-HRE-Luc-eGFP construct. Prior to using the LNT-HRE-Luc-eGFP vector to interrogate signaling profiles in disease models in vivo, it was important to first validate this construct and establish its ability to be induced by agonists in vitro. $\mathrm{CoCl}_{2}$ is a chemical inducer of the hypoxiainducible factor that mimics hypoxia. In the presence of $\mathrm{CoCl}_{2}$, a highly significant increase in luciferase-mediated bioluminescence fold-change ( $\Delta$ bioluminescence) over non-activated cells was observed in vitro (Figure $2^{15}$ ) prior to in vivo (Figure $3^{15}$ ) validation and experimentation.

Response to oxygen content of carrier gasses during anesthesia. Following validation of the hypoxia response element in vitro, we chose to use it to ask whether in vivo HIF activity is modulated by the anesthetic carrier gas. $100 \%$ oxygen is frequently used as a carrier gas to ensure sufficient tissue oxygenation during anesthesia however, theoretically, it may downregulate HIF activation as this response element responds inversely to hypoxia, or the lack of oxygen. Mice underwent anesthesia with isoflurane using either air or $100 \%$ oxygen as the carrier gas and HRE signaling monitored at a series of time points using bioluminescence imaging. A change in bioluminescence ( $\Delta$ bioluminescence) compared to time point 0 was noted over time with oxygen expectedly decreasing the expression of the HIF response element (Figure $3 \mathrm{~A}-\mathrm{B}^{15}$ ). This indicates the importance of selecting the correct carrier gas for anaesthetic induction when interrogating HIF-responsive signaling using luciferase expression and imaging.

Somatotransgenic bioimaging to assess GFAP activation in a model of cholestatic liver injury. The partial BDL model is an established model of cholestatic liver disease ${ }^{17}$. Currently, analysis of liver disease consists of terminal endpoint analysis of groups of animals at serial time points, and/or serial bleedings for analysis of serological biomarkers of liver function, particularly liver enzymes and total serum bile acids. We have previously studied signal transduction pathways of inflammation and WNT-signaling in this model ${ }^{14}$. Here, we asked whether expression of GFAP, a marker of activated hepatic stellate cells that are a major cell type involved in liver fibrosis, was altered following induction of liver injury. P1 mice received LNT-GFAP-Luc-eGFP, a lentiviral vector containing the luciferase-eGFP transgene driven by the bioresponsive glial fibrillary acidic protein (GFAP) response element. At 45 days of age mice were randomly allocated to two groups, one of which received partial bile duct ligation; controls received sham surgery without ligation of the bile duct (Figure $4 \mathrm{~A}-\mathrm{B}^{15}$ ). There was a consistent increase in bioluminescence 3 days after induction of the model versus sham controls. One particular mouse showed a remarkable, sustained increase in luciferase output following induction. This data illustrates the strength of continual non-invasive measurements, in that it is possible to identify consistent outliers, which would not be possible with terminal end-point analysis, due to a lack of data on expression kinetics.

\section{Discussion}

The development of the described methodologies has a broad scope of applicability for monitoring of disease progression, induction, and therapeutic intervention. The generation of biosensing, reporter animals that can undergo longitudinal assessment of transcription factor activity has significant implications for the number of animals currently being utilized within both academic and industry research and development. This novel platform of somatotransgenic bioimaging is also capable of generating longitudinal datasets from small cohorts of animals. F0 cohorts based on appropriate power calculations can be
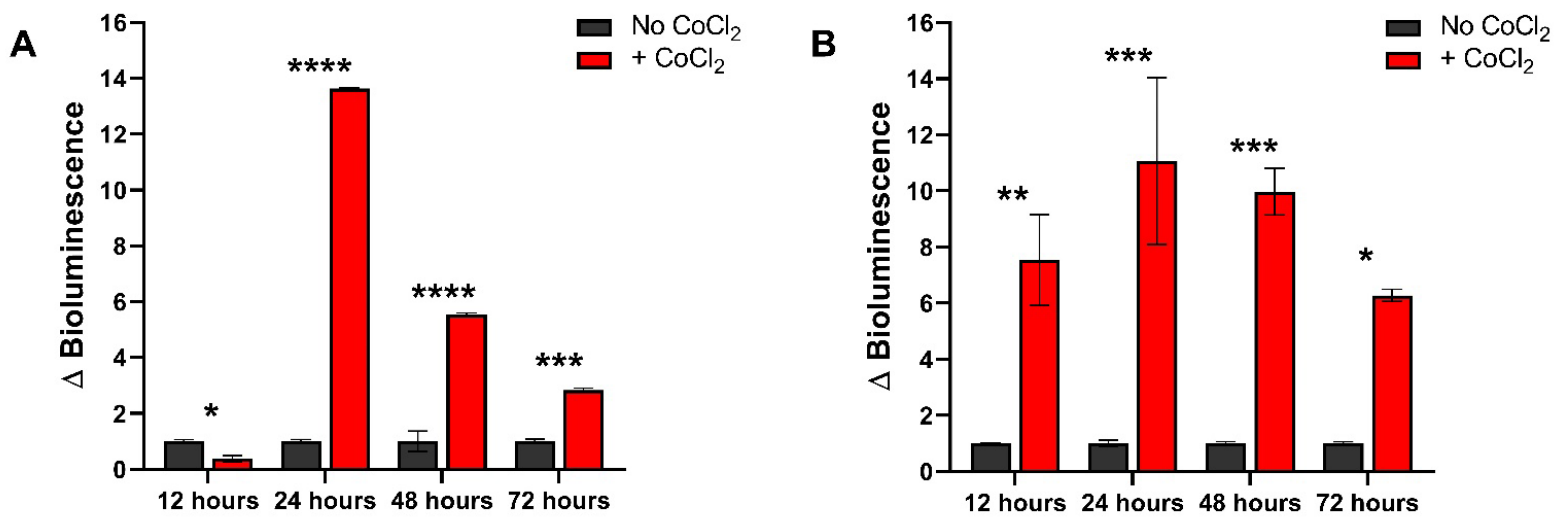

Figure 2. In vitro validation of LNT-HRE-Luc-eGFP. HEK293T (A) and HeLa (B) cells were transduced with pLNT-HRE-Luc-eGFP and either activated ( $n=3)$ with $250 \mu \mathrm{M} \mathrm{CoCl}_{2}$ (red bars) or not activated ( $\left.n=3\right)$ (grey bars) in triplicate for each of the time points $(T=12,24,48$, and 72 hours). Data was analyzed using a two-way ANOVA with repeated measures with Bonferroni post-hoc test to correct for multiple testing. Bars represent mean \pm SD with adjusted p values indicated above each timepoint $\left(*=<0.05,{ }^{*}=<0.01,{ }^{* *}=<0.001,{ }^{* * * *}=<0.0001\right)$. 

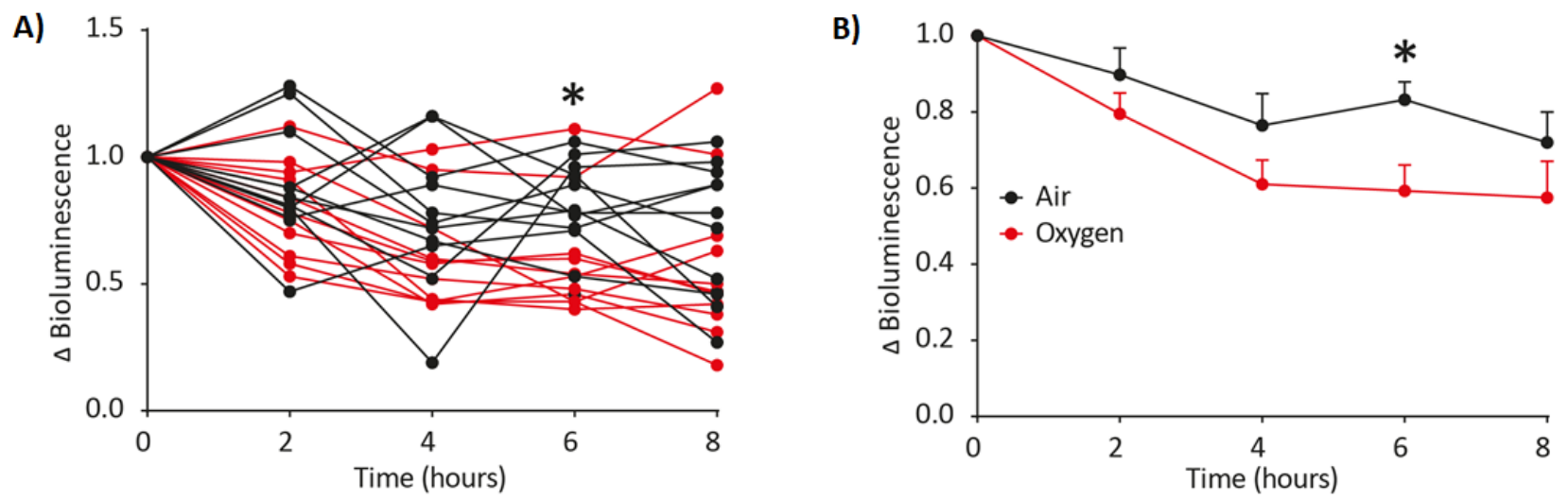

Figure 3. Response of HIF response element (HRE) signaling when anesthetized using $100 \%$ oxygen or air carrier gas. LNT-HRE-Luc-eGFP transduced animals were imaged at 0,2,4,6 and 8 hours in either 100\% oxygen ( $n=11$ ) (red) or air ( $n=11)($ black) carrier gas. An increase in oxygen results in lower hypoxia-induced luciferase expression with data expressed as a fold change in bioluminescence ( $\Delta$ bioluminescence) from time point $0 . \Delta$ Bioluminescence was plotted per individual animal (A) and as mean $\pm S D(B)$. Statistical significance of $>0.05$ is indicated by * (Sidak's multiple comparison test, Graphpad Prism 8.0).
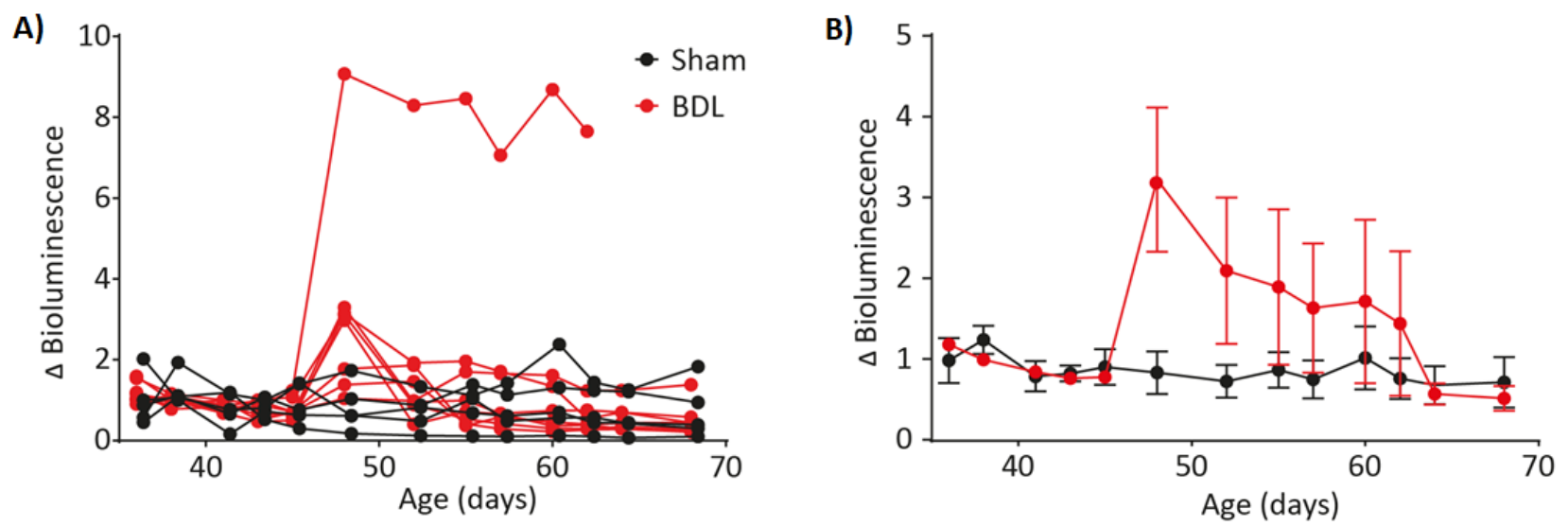

Figure 4. GFAP promoter activity following partial bile duct ligation. LNT-GFAP-Luc-eGFP-transduced animals were subject to partial bile duct ligation $(n=7)($ red) as a model of cholestatic liver injury. Another group of animals underwent sham surgery only ( $n=5)(b l a c k)$. Fold-change in bioluminescence ( $\Delta$ bioluminescence) was calculated before and after model induction and plotted as individual animals (A) and means \pm SD (B).

administered with TFAR vector and assayed almost immediately, depending on the experiment, after drug administration or disease state induction. In many instances, animals can be reused for further follow-up studies without any due stress or requirement for serial anesthesia. This approach results in a massive reduction in animals required for a predicted outcome and a clear decrease in procedures stressful to animals.

\section{Data availability}

Underlying data

Open Science Framework: Non-invasive somatotransgenic bioimaging in living animals. https://doi.org/10.17605/OSF.IO/ $\mathrm{XF} \mathrm{EZ}^{15}$
This project contains the following underlying data:

1. 293T - HRE $-\mathrm{CoCl}_{2}$ - Luciferase assay calculations.csv - (in vitro luciferase assay using the LNT-HRE-Luc-eGFP and cobalt chloride agonist in HEK293T cells).

2. $\mathrm{HeLa}-\mathrm{HRE}-\mathrm{CoCl}_{2}-$ Luciferase assay calculations.csv - (in vitro luciferase assay using the LNT-HRE-Luc-eGFP and cobalt chloride agonist in HeLa cells).

3. BDL NC3Rs raw data.csv - (In vivo raw data for GFAP activation using bile duct ligations (BDL)).

4. HRE NC3Rs raw data.csv - (In vivo raw data for HRE activation using the model of hypoxia). 
5. pLNT-GW-Luc-eGFP.dna - (plasmid map of the lentiviral construct containing the Gateway cassette upstream of luciferase and eGFP).

6. pLNT-HRE-Luc-eGFP.dna - (plasmid map of the lentiviral construct containing the HIF response element (HRE) upstream of luciferase and eGFP following recombination).

7. Gel image -eGFP before recombination.tif - (BamHI digest of LNT-GW-Luc-eGFP prior to recombination reaction).
8. BamHI digest of pLNT-HRE, WNT, PI3, HNF4, Gli-Luc-eGFP clones.tif - (BamHI digest of LNT-HRE, WNT, PI3, HNF4, Gli-Luc-eGFP response elements following recombination reaction).

9. pLNT-HRE-Luc-eGFP sequencing to confirm HRE. abi - (sequencing of LNT-HRE-JDG and alignment to theoretical sequence of LNT-HRE-JDG).

Data are available under the terms of the Creative Commons Zero "No rights reserved" data waiver (CCO 1.0 Public domain dedication).
1. Wilson T, Hastings JW: Bioluminescence. Annu Rev Cell Dev Biol. 1998; 14: 197-230.

PubMed Abstract | Publisher Full Text

2. Buckley SMK, Delhove JMKM, Perocheau DP, et al.: In vivo bioimaging with tissue-specific transcription factor activated luciferase reporters. Sci Rep. 2015; 5: 11842.

PubMed Abstract | Publisher Full Text | Free Full Text

3. Dodd KW, Burns TC, Wiesner SM, et al.: Transgenic mice expressing luciferase under a 4.5 kb tyrosine hydroxylase promoter. Cureus. 2011; 3(8): e34. Publisher Full Text

4. Rojas-Fernandez A, Herhaus L, Macartney T, et al.: Rapid generation of endogenously driven transcriptional reporters in cells through CRISPR/ Cas9. Sci Rep. 2015; 5: 9811.

PubMed Abstract | Publisher Full Text | Free Full Text

5. Office UH: Annual statistics of scientific procedures on living animals Great Britain 2015. 2013.

Reference Source

6. Zhang N, Ahsan MH, Purchio AF, et al.: Serum amyloid A-luciferase transgenic mice: response to sepsis, acute arthritis, and contact hypersensitivity and the effects of proteasome inhibition. J Immunol. 2005; 174(12): 8125-8134. PubMed Abstract | Publisher Full Text

7. Karda R, Delhove JM, Buckley SM, et al.: Generation of Light-Emitting Somatic-Transgenic Mice for Disease Modelling of Hypoxic Ischaemic Encephalopathy. Reprod Sci. 2015; 22: 174A-174A.

8. Wu L, Zhao $\mathrm{H}$, Weng $\mathrm{H}$, et al.: Lasting effects of general anesthetics on the brain in the young and elderly: "mixed picture" of neurotoxicity, neuroprotection and cognitive impairment. J Anesth. 2019; 33(2): 321-335. PubMed Abstract | Publisher Full Text | Free Full Text

9. Karda R, Perocheau DP, Suff N, et al.: Continual conscious bioluminescent imaging in freely moving somatotransgenic mice. Sci Rep. 2017; 7(1): 6374 PubMed Abstract | Publisher Full Text | Free Full Text
10. Fagone P, Wright JF, Nathwani AC, et al.: Systemic errors in quantitative polymerase chain reaction titration of self-complementary adenoassociated viral vectors and improved alternative methods. Hum Gene Ther Methods. 2012; 23(1): 1-7.

PubMed Abstract | Publisher Full Text | Free Full Text

11. Zeltner $\mathrm{N}$, Kohlbrenner $\mathrm{E}$, Clément $\mathrm{N}$, et al.: Near-perfect infectivity of wildtype AAV as benchmark for infectivity of recombinant AAV vectors. Gene Ther. 2010; 17(7): 872-879.

PubMed Abstract | Publisher Full Text | Free Full Text

12. Kim JY, Ash RT, Ceballos-Diaz C, et al.: Viral transduction of the neonatal brain delivers controllable genetic mosaicism for visualising and manipulating neuronal circuits in vivo. Eur J Neurosci. 2013; 37(8): 1203-1220. PubMed Abstract | Publisher Full Text | Free Full Text

13. Yang $\mathrm{M}$, Ramachandran $\mathrm{A}$, Yan $\mathrm{HM}$, et al: Osteopontin is an initial mediator of inflammation and liver injury during obstructive cholestasis after bile duct ligation in mice. Toxicol Lett. 2014; 224(2): 186-195. PubMed Abstract | Publisher Full Text | Free Full Text

14. Delhove JMKM, Buckley SMK, Perocheau DP, et al.: Longitudinal in vivo bioimaging of hepatocyte transcription factor activity following cholestatic liver injury in mice. Sci Rep. 2017; 7: 41874. PubMed Abstract | Publisher Full Text | Free Full Text

15. Delhove J: Non-invasive somatotransgenic bioimaging in living animals. 2020. http://wwww.doi.org/10.17605/OSF.IO/XF7EZ

16. Diaz JA, Geard A, FitzPatrick LM, et al.: Continual Conscious Bioluminescent Imaging in Freely Moving Mice. Methods Mol Biol. 2020; 2081: $161-175$.

PubMed Abstract | Publisher Full Text

17. Heinrich $S$, Georgiev $P$, Weber A, et al.: Partial bile duct ligation in mice: a novel model of acute cholestasis. Surgery. 2011; 149(3): 445-451.

PubMed Abstract | Publisher Full Text 


\section{Open Peer Review}

\section{Current Peer Review Status: ? ? ?}

Version 1

Reviewer Report 13 December 2021

https://doi.org/10.5256/f1000research.27891.r96779

(c) 2021 Gavins F. This is an open access peer review report distributed under the terms of the Creative Commons Attribution License, which permits unrestricted use, distribution, and reproduction in any medium, provided the original work is properly cited.

\section{Felicity Gavins}

Department of Life Sciences, Centre for Inflammation Research and Translational Medicine (CIRTM), Brunel University London, Uxbridge, UK

This manuscript by Delhove et al., focusses on trying to address some of the issues that surround the use of bioluminescence imaging e.g. the wastage of large numbers of animals, unwanted background luciferase activity during bioluminescent imaging, and the time consuming and costly process of genome editing for luciferase transgene expression. To overcome these issues, the authors developed tissue-restricted transcription factor activated luciferase reporter (TFAR) cassettes in animals (a method termed 'somatotransgenic bioimaging').

Overall, this is a nicely written and interesting methodology article. The fact that the authors have been developing and fine tuning their methodology over the last few years, makes the protocol one which is likely to be taken up by other researchers wanting to perform bioluminescence imaging or more specifically, somatotransgenic bioimaging, to address their scientific questions. That being said, it would have been nice to see a more open and easily accessible way for researchers to be able to have access to the TFARs, rather than solely gaining access on request. In addition, it would have been helpful to have more information regarding the impact and uptake of this type of methodology, especially in the context of the 3Rs in other areas of research, not just in the context of liver disease models.

The 3Rs benefit seems somewhat inflated with respect to the numbers of animals that could be reduced if somatotransgenic bioimaging were performed. The authors discuss that in their longitudinal imaging experiments they use 6-8 somatotransgenic experimental and 6-8 control animals per experiment, which translates into 7-10 fold reduction in the number of animals used in liver disease models as compared to the current standard methodologies of analysis. However, while there is no doubt that the use of somatotransgenic bioimaging may reduce animal use, the reduction proposed may be higher than that suggested by the authors because e.g. the periodic sacrifice for histological analysis may still be needed, especially by other groups.

Table 1 is useful, but references for each response element would be helpful. In addition, the 
response elements used in the figures do not seem to be present in the table. These should be added.

The conscious imaging element that the authors proposed is interesting and physiologically relevant. However, is the imaging only possible using the specific custom-made "periscopic chamber to permit simultaneous collection of light emission from both ventral and dorsal surfaces" (Karda et al., 2017)?

Under the paragraph entitled 'Whole-body bioluminescence imaging', it is not clear as to whether the ip injection of D-luciferin was administered per gram weight of the animal.

The notes provided in the methods section are helpful. However, as this is a method article of a novel methodology, more information should be provided. This may also increase uptake of this specific method e.g. can the authors provide data obtained for the alternative routes of administration of the D-lucferin,

The authors mention that it is best to use "white-furred mice as the black-furred mice prevent the bioluminescence from penetrating through". Given the number of transgenic animals that are on C57BI/6 background, this statement would seem rather confusing. Would the authors provide more information as to how researchers should deal with these issues e.g. shaving of the mice.

Providing kinetic experiments of D-luciferin for different cell and tissue targets would be a helpful addition.

Figure 1 seems to be missing, or the figures are incorrectly labelled?

Figure 2. Baseline $(\mathrm{t}=0 \mathrm{~h})$ levels should be provided.

Figure legends need more information so that the reader does not need to refer back to the article e.g. Figure 3 "transduced animals were imaged....". Where were they imaged? More details needed regarding the TFAR.

No imaging pictures have been provided. These should be included.

Figure 4 is lacking statistics. If nothing was significant, this should be made clear in the figure legend and article text.

Are a suitable application and appropriate end-users identified?

Yes

If applicable, is the statistical analysis and its interpretation appropriate?

Yes

Are the 3Rs implications of the work described accurately?

Partly

Is the rationale for developing the new method (or application) clearly explained? 
Yes

Is the description of the method technically sound?

Yes

Are sufficient details provided to allow replication of the method development and its use by others?

Partly

If any results are presented, are all the source data underlying the results available to ensure full reproducibility?

Partly

Are the conclusions about the method and its performance adequately supported by the findings presented in the article?

Yes

Competing Interests: No competing interests were disclosed.

Reviewer Expertise: Inflammation and immune cell trafficking, pharmacology and preclinical imaging. Referee suggested by the NC3Rs for their scientific expertise and experience in assessing 3Rs impact.

I confirm that I have read this submission and believe that I have an appropriate level of expertise to confirm that it is of an acceptable scientific standard, however I have significant reservations, as outlined above.

Reviewer Report 16 November 2020

https://doi.org/10.5256/f1000research.27891.r73989

(C) 2020 Plagge A. This is an open access peer review report distributed under the terms of the Creative Commons Attribution License, which permits unrestricted use, distribution, and reproduction in any medium, provided the original work is properly cited.

\section{Antonius Plagge}

Department of Molecular Physiology \& Cell Signalling, Institute of Systems, Molecular \& Integrative Biology, University of Liverpool, Liverpool, UK

Delhove et al. describe Lenti- and Adenovirus vector-based methods to generate and analyse somatotransgenic mice that express firefly luciferase as a reporter gene to monitor via bioluminescene the response of transfected cells or tissues to various stimuli. They generated a Gateway system to easily add genetic promoter/response elements to a bicistronic cassette of Luc and eGFP. They describe a range of tested artificial promoter response elements (TFARs), which contain multiple copies of specific transcription factor binding sites and are useful to monitor certain physiological or developmental processes like hypoxia. Virus particles containing such 
reporter constructs are injected into neonatal mice, leading to transfection of endogenous cells in the surrounding tissue, which then permanently express luciferase and GFP. The authors demonstrate their techniques with the hypoxia induced response element (HRE) and a GFAP response element in in vitro and in vivo experiments. This protocol is supported by several publications from this author group over the last $\sim 5$ years, in which they continuously developed and refined their methods. In my view, this approach of somatotransgenic luciferase reporter gene mice, which cannot be maintained by breeding and need to be generated newly for each experiment, can be useful in some experimental set-ups, but cannot fully replace germline transgenic or knock-in mice that express luciferase from cell-type specific promoters. The manuscript is overall well written and detailed, thus allowing replication of the methods by other groups. The authors mentioned that they would distribute their plasmid constructs upon request, but I was wondering whether they are considering to deposit them with Addgene for easier and more general availability?

The injection of virus particles into neonatal mice (intracranial, iv) requires training and well developed skills. The authors didn't really comment on potential side effects from such procedures. For example, what are the chances that mice develop permanent brain damage following intracranial virus injections? What is the rate of losses of neonatal mice following injections? Such details should be discussed in the paper.

The virus injections might label various cell types in the tissue or region surrounding the injection site. The response of those cell types to the challenge provided, e.g. hypoxia, might differ and this might therefore not be recognised with this approach. Can this be discussed in more detail?

The authors should add references to table 1 TFARS, where validated by publications. The last factor cassette TFEB / autophagy seems to be limited to cell culture? Please clarify.

Note 12 on page 11 - subcutaneous luciferin injection should be added as a recommended (Perkin Elmer) alternative injection route.

Page 12 top: "Here we present data validating our biosensing constructs in vitro (Figure 1) prior to in vivo (Figure 2) validation and experimentation." Should read Figures 2 and 3

Figure 3 legend: please clarify whether these were intracranial injections.

The GFAP promoter/response element used in Figure 4 does not seem to be listed in table 1? Please clarify and provide more detail.

Please clarify for all relevant figures whether $\Delta$ Bioluminescence is based on difference in radiance (photons/sec/cm2/sr) or on difference in Flux (photons/sec).

\section{Are a suitable application and appropriate end-users identified?}

Yes

If applicable, is the statistical analysis and its interpretation appropriate? Yes

Are the 3Rs implications of the work described accurately? 
Yes

Is the rationale for developing the new method (or application) clearly explained?

Yes

Is the description of the method technically sound?

Yes

Are sufficient details provided to allow replication of the method development and its use by others?

Yes

If any results are presented, are all the source data underlying the results available to ensure full reproducibility?

Yes

Are the conclusions about the method and its performance adequately supported by the findings presented in the article?

Yes

Competing Interests: No competing interests were disclosed.

Reviewer Expertise: neurobiology, lentivirus vectors, bioluminescence, preclinical imaging, genetically modified mouse models, epigenetics, genomic imprinting, neuroendocrinology,

I confirm that I have read this submission and believe that I have an appropriate level of expertise to confirm that it is of an acceptable scientific standard, however I have significant reservations, as outlined above.

Reviewer Report 03 November 2020

\section{https://doi.org/10.5256/f1000research.27891.r72772}

(C) $2020 \mathrm{Xu}$ T. This is an open access peer review report distributed under the terms of the Creative Commons Attribution License, which permits unrestricted use, distribution, and reproduction in any medium, provided the original work is properly cited.

\section{Tingting $\mathbf{X u}$}

Center for Environmental Biotechnology, The University of Tennessee, Knoxville, TN, USA

This manuscript describes the somatotransgenic bioimaging technology in living mice using transcription factor activated luciferase reporter (TFAR) delivered by viral vectors. Specifically, the manuscript describes in detail: 1) design and cloning of transcription factor-minimal promoters, 2) design and production of lentiviral and adeno-associated viral delivery vectors, 3) imaging of HIF response element in response to different anesthesia carrier gas, and 4) imaging of GFAP activity in liver injury. Overall, the somatrotransgenic bioimaging technology is advantageous over the 
traditional transgenic model by significantly reducing the number of animals needed. This manuscript also demonstrates imaging in conscious animals which further reduces animal stressed associated with anesthesia.

Some details of the method/protocol is missing:

1. Page 8 , left column, under 'Whole-body bioluminescence imaging. How many mg D-luciferin per $g$ of body weight?

2. Page 10 , left column, bullet point 18 . What serial dilutions were used as standards?

3. Page 11, right column, bullet points 12 and 13 . Please provide more details about how to perform these preliminary experiments.

Data still needed to support the conclusion:

1. In vitro validation data of GFAP reporter

2. Actual animal images of Figure 3 and Figure 4. This is an animal bioimaging manuscript after all. Need the animal photos.

3. Page 13, figure 4: Any statistics performed to compare the Sham and BDL groups? Other formatting issues:

1. Page 12, left column, top 3 lines: Double check the figure numbers. They don't match.

2. Page 11, left column, subtitles 'neonatal intracranial and intravenous injections' and 'continued monitoring of TFAR activity in anesthetised or conscious mice' : double check their formatting. As of now they appear to be part of notes, but they should be the subheadings for protocols.

Are a suitable application and appropriate end-users identified?

Yes

If applicable, is the statistical analysis and its interpretation appropriate? Yes

Are the 3Rs implications of the work described accurately?

Yes

Is the rationale for developing the new method (or application) clearly explained?

Yes

Is the description of the method technically sound?

Yes

Are sufficient details provided to allow replication of the method development and its use by others?

Partly

If any results are presented, are all the source data underlying the results available to 
ensure full reproducibility?

Partly

Are the conclusions about the method and its performance adequately supported by the findings presented in the article?

Yes

Competing Interests: No competing interests were disclosed.

Reviewer Expertise: bioimaging, bioreporter

I confirm that I have read this submission and believe that I have an appropriate level of expertise to confirm that it is of an acceptable scientific standard, however I have significant reservations, as outlined above.

The benefits of publishing with F1000Research:

- Your article is published within days, with no editorial bias

- You can publish traditional articles, null/negative results, case reports, data notes and more

- The peer review process is transparent and collaborative

- Your article is indexed in PubMed after passing peer review

- Dedicated customer support at every stage

For pre-submission enquiries, contact research@f1000.com 